\title{
Correlation between local Fe states and magnetoresistivity in granular films containing FeCoZr nanoparticles embedded into oxygen-free dielectric matrix
}

\author{
J.V. Kasiuk ${ }^{\text {a }}$, J.A. Fedotova ${ }^{\text {a }}$, T.N. Koltunowicz ${ }^{\text {b,* }}$, P. Zukowski ${ }^{\text {b,* }}$, A.M. Saad ${ }^{\text {c }}$, J. Przewoznik ${ }^{\text {, }}$, \\ Cz. Kapusta ${ }^{\mathrm{d}}$, J. Zukrowski ${ }^{\mathrm{d}}$, I.A. Svito ${ }^{\mathrm{e}}$ \\ ${ }^{a}$ NC PHEP Belarusian State University, 220040 Minsk, Belarus \\ ${ }^{\mathrm{b}}$ Lublin University of Technology, 20-618 Lublin, Poland \\ ${ }^{\mathrm{c}}$ Al-Balqa Applied University, 11953 Amman, Salt, Jordan \\ ${ }^{\mathrm{d}}$ AGH University of Science and Technology, 30-059 Krakow, Poland \\ ${ }^{\mathrm{e}}$ Belarusian State University, 220030 Minsk, Belarus
}

\section{A R T I C L E I N F O}

\section{Article history:}

Available online 23 September 2012

\section{Keywords:}

Nanocomposites

Magnetoresistance

Mössbauer spectroscopy

\begin{abstract}
A B S T R A C T
The paper reports on a comparative study of local Fe states, phase composition and magnetoresistivity of granular nanocomposite films FeCoZr- $-\mathrm{CaF}_{2}$ sintered in pure $\mathrm{Ar}$ and $\mathrm{Ar}+\mathrm{O}$ sputtering atmosphere. For the first time peculiarities of temperature and magnetic field dependencies of magnetoresistance are analyzed with respect to partial oxidation of nanoparticles and perpendicular magnetic shape anisotropy.
\end{abstract}

(c) 2012 Elsevier B.V. All rights reserved.

\section{Introduction}

The requirements to modern materials that are prospective for magnetoelectronic devices operating at frequencies up to $\mathrm{GHz}$ range include high saturation magnetization and electrical resistivity, high permeability and low magnetic losses combined with technological possibility to form miniature devices. Recent experiments have proven that granular nanocomposite metal-dielectric films, where Fe, Co-based nanoparticles (3-10 nm) are dispersed inside insulating matrixes $\left(\mathrm{Al}_{2} \mathrm{O}_{3}, \mathrm{SiO}_{2}\right.$, etc.), fully satisfy these requirements [1,2]. Granular films containing soft $\mathrm{FeCo}(\mathrm{B}, \mathrm{Si})-$ based nanoparticles showed high magnetization, permeability and electrical resistivity and also its relatively high sensitivity to external magnetic field $H$. The highest negative tunneling magnetoresistive effect $(M R)$ was observed in $\mathrm{Co}-\mathrm{MgF}_{2}$ granular films and reached $25 \%$ at $H=10 \mathrm{kOe}$ and $T=5 \mathrm{~K} \mathrm{[2]}$.

The direction of further improvement of properties of the films is related to application of oxygen-free matrices, like $\mathrm{CaF}_{2}, \mathrm{MgF}_{2}$, in granular films that should prevent undesirable oxidation of metallic nanoparticles. On the other hand, it is proven experimentally that the formation of nanoparticles with "metal core - oxide shell" structure during sputtering of films in mixed $\mathrm{Ar}+\mathrm{O}_{2}$ atmosphere

\footnotetext{
* Corresponding authors. Fax: +48 815384575 (T.N. Koltunowicz), fax: +48 81 5384575 (P. Zukowski).

E-mail addresses: t.koltunowicz@pollub.pl (T.N. Koltunowicz),pawel@elektron. pol.lublin.pl (P. Zukowski).
}

resulted in the increase of negative $M R$ [3]. In so doing, study of phase composition, Fe local states and magnetoresistivity of FeCoZr- $-\mathrm{CaF}_{2}$ granular films with tailored composition should elucidate the effect of oxygen containing atmosphere on the controlled variation of structure and magnetotransport properties of films.

\section{Experimental}

Granular films $\left(\mathrm{Fe}_{45} \mathrm{Co}_{45} \mathrm{Zr}_{10}\right)_{x}\left(\mathrm{CaF}_{2}\right)_{100-x}, 16$ at.\% $\leqslant x \leqslant 75$ at.\% of $1-6 \mu \mathrm{m}$ thickness were deposited by ion-beam sputtering of complex target in $\mathrm{Ar}$ and $\mathrm{Ar}+\mathrm{O}_{2}$ atmospheres $\left(P_{\mathrm{O}}=4.3\right.$ and $\left.9.8 \mathrm{mPa}\right)$ on glass-ceramic and Al substrate. Phase composition and structure of films was analyzed by Empyrean PANalytical diffractometer using $\mathrm{Cu} \mathrm{K} \mathrm{K}_{\alpha}$ radiation and a graphite monochromator at the diffracted beam at the grazing incidence angle of $5^{\circ}$. Local Fe states were analyzed by transmission ${ }^{57} \mathrm{Fe}$ Mössbauer spectroscopy with ${ }^{57} \mathrm{Co} / \mathrm{Rh}$ source. Field and temperature dependences of electrical resistance $R(H, T)$ were measured by two-probe method using High Field Measurement System in the magnetic field $H$ up to 80 kOe and temperature range $T=10-300 \mathrm{~K}$.

\section{Results and discussion}

XRD patterns of $(\mathrm{FeCoZr})_{\mathrm{x}}\left(\mathrm{CaF}_{2}\right)_{100-\mathrm{x}}(29 \leqslant \mathrm{x} \leqslant 73$ at.\%) granular films deposited in Ar atmosphere $\left(P_{\mathrm{O}}=0\right)$ on $\mathrm{Al}$ substrates are presented in Fig. 1a. One should note broad reflections from $f c c \mathrm{CaF}_{2}$ matrix $(a=5.48-5.52 \AA)$ and $b c c \alpha-\mathrm{Fe}(\mathrm{Co})$ alloy $(a=2.86-2.95 \AA)$ phases as well as some much sharper reflections arising from $\mathrm{Al}$ substrate. Reflections from several crystallographic planes appear for films with lowest $\mathrm{x}$ and with highest $x$, respectively for $\mathrm{CaF}_{2}$ 

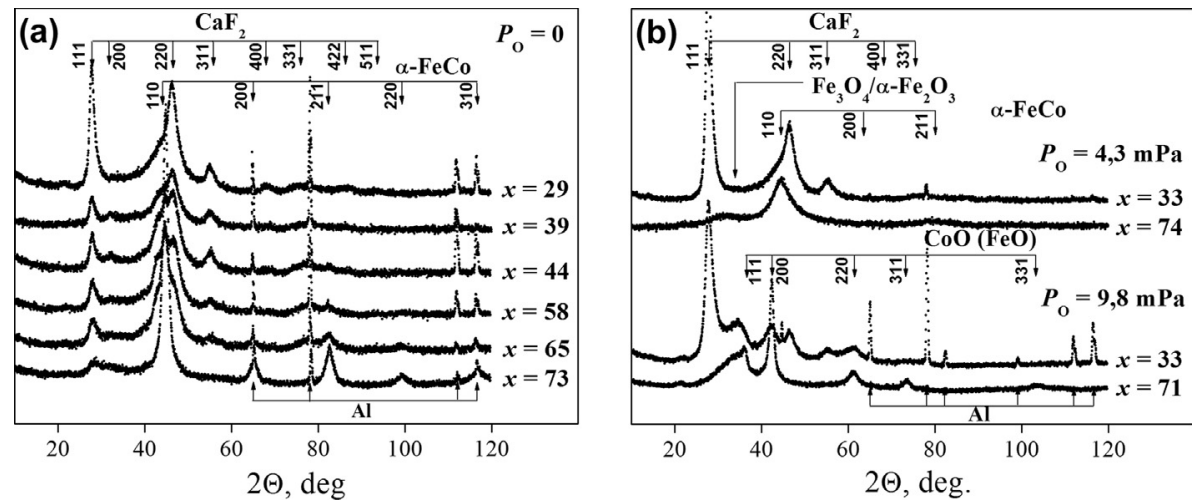

Fig. 1. Selected XRD patterns of $(\mathrm{FeCoZr})_{x}\left(\mathrm{CaF}_{2}\right)_{100-x}\left(29 \leqslant x \leqslant 73\right.$ at.\%) granular films sintered in $\mathrm{Ar}(\mathrm{a})$ and $\mathrm{Ar}+\mathrm{O}_{2}(\mathrm{~b})$ atmospheres.

and for $\alpha$-Fe(Co) structures, indicating relatively higher degree of crystallinity of these phases in corresponding composition ranges.

A closer inspection of XRD patterns for films with $x=44-65$ at.\% shows coexistence of two bcc $\alpha-\mathrm{Fe}(\mathrm{Co})$ type phases with overlapping peaks, one with much sharper lines and unit cell parameter values expected for non-oxidized alloy [3] and the other one with much broader peaks, noticeably larger unit cell parameter and its amount decreasing with increasing $x$. Such a diversification of the $\alpha-\mathrm{Fe}(\mathrm{Co})$ nanograins occurs the most probably due to formation of a less crystallized outer shell with slightly increased $a$ parameter and practically stoichiometric, better crystallized core of the nanograin.

Selected XRD patterns of granular films sintered in $\mathrm{Ar}+\mathrm{O}_{2}$ atmosphere at $P_{\mathrm{O}}=4.3 \mathrm{mPa}$ (see Fig. 1b, upper panel) show few broad reflections corresponding to $\mathrm{CaF}_{2}$ matrix and $\alpha-\mathrm{Fe}(\mathrm{Co})$ nanoparticles. Additional broad reflection around $2 \theta=33-34^{\circ}$ is assigned to $\mathrm{Fe}_{3} \mathrm{O}_{4}$ or $\alpha-\mathrm{Fe}_{2} \mathrm{O}_{3}$ phases. Further increase of partial oxygen pressure up to $P_{\mathrm{O}}=9.8 \mathrm{mPa}$ resulted in the formation of crystalline $f c c \mathrm{CoO}(\mathrm{FeO})(a=4.26-4.31 \AA$ ) phase (see Fig. $1 \mathrm{~b}$, lower panel). No evidence of $\alpha-\mathrm{Fe}(\mathrm{Co})$ phase was found in the corresponding patterns confirming full oxidation of metallic nanoparticles.

Mössbauer spectra of $(\mathrm{FeCoZr})_{x}\left(\mathrm{CaF}_{2}\right)_{100_{-x}}$ films with low alloy content ( $x \sim 39$ at.\%, see Fig. $2 a$ ) consist of dominating nonmag- netic and magnetically split contributions. The hyperfine parameters extracted correspond to $\alpha$ - $\mathrm{FeCo}(\mathrm{Zr})$ superparamagnetic (SP) nanoparticles [3]. An intermediate $\mathrm{x} \sim 44$ at.\% spectra show the superposition of SP contribution and magnetically split subspectrum, which becomes dominating and reveal magnetic interaction between nanoparticles through insulating $\mathrm{CaF}_{2}$ matrix. Mössbauer spectra of films with highest $x(\sim 73$ at.\%) are well magnetically split due to advanced magnetic interaction between $\alpha$-FeCo $(Z r)$ nanoparticles. The boundary value of $x$ for the magnetically ordered state of the nanocomposite film at room temperature is about 39 at.\%.

The peculiar feature of Mössbauer spectra at $x \approx 73$ at.\% is the relative intensity of spectral lines $h_{3}: h_{2}: h_{1}$ close to 3: 0.3:1 (see Fig. 2a) that is typical for perpendicular orientation of magnetic moments of the film with respect to its surface. The angle $\theta$ between $\gamma$-quanta direction and orientation of magnetic moments is estimated by the relationship $\theta=\arccos [(4-K) /(4+K)]^{1 / 2}[4]$, where $K=h_{2}: h_{1}$ and comprise $\theta \sim 20^{\circ}$. In accordance with [5], the observed magnetic anisotropy is related to the shape anisotropy of nanoparticles due to their growth in the form of columnar structures.

Mössbauer spectra of oxidized FeCoZr $-\mathrm{CaF}_{2}$ films (at $P_{\mathrm{O}}=4.3-$ $\mathrm{mPa}$ ) are shown in Fig. 2b. Spectra of films with $\mathrm{x}$ around 36 at.\% were fitted assuming two quadrupole doublets $D^{3+}(\delta=0.42 \mathrm{~mm} / \mathrm{s}$;
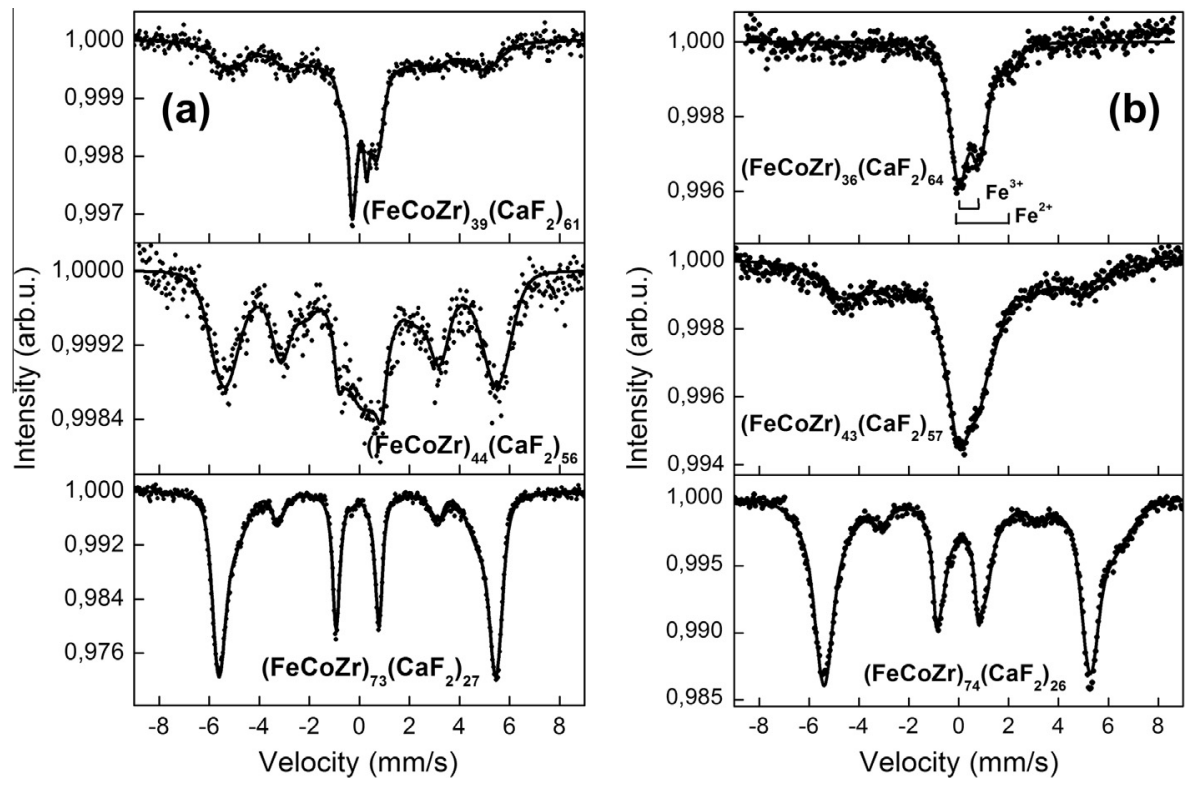

Fig. 2. Mössbauer spectra of $(\mathrm{FeCoZr})_{x}\left(\mathrm{CaF}_{2}\right)_{100-\mathrm{x}}\left(29 \leqslant \mathrm{x} \leqslant 73\right.$ at.\%) granular films deposited on $\mathrm{Al}$ foil in $\mathrm{Ar}(\mathrm{a})$ and $\mathrm{Ar}+\mathrm{O}_{2}$ at $P_{\mathrm{O}}=4.3 \mathrm{mPa}(\mathrm{b})$ atmospheres. 
$\Delta=0.82 \mathrm{~mm} / \mathrm{s})$ and $D^{2+}(\delta=0.95 \mathrm{~mm} / \mathrm{s} ; \quad \Delta=2.07 \mathrm{~mm} / \mathrm{s})$ that correspond to $\mathrm{Fe}^{3+}$ and $\mathrm{Fe}^{2+}$ in iron-based oxides that well correlates with XRD patterns where $\mathrm{Fe}_{3} \mathrm{O}_{4}$ and/or $\alpha-\mathrm{Fe}_{2} \mathrm{O}_{3}$ phases were identified. It is noteworthy that no subspectra assigned to nonoxidized SP $\alpha$ - $\mathrm{FeCo}(\mathrm{Zr})$ nanoparticles were detected in this composition range. The spectrum of film with $x=43$ at.\% reveals intermediate magnetic state containing magnetically collapsed sextet $\alpha-\mathrm{FeCo}(\mathrm{Zr})$ and SP contribution of iron oxides. Spectra also evidence a shift of threshold $x$ for SP-FM transition towards higher values as compared to non-oxidized films. This is due to a suppression of coupling of nanoparticles with oxide shells formation. Such phenomenon was first observed and interpreted in $\mathrm{FeCoZr}-\mathrm{Al}_{2} \mathrm{O}_{3}$ films [3]. Mössbauer spectra of films with $\mathrm{x}=74$ at.\% show a superposition of two magnetically split contributions - non-oxidized $\alpha$ - FeCo(Zr) $\left(\delta \sim 0 \mathrm{~mm} / \mathrm{s},<H_{\mathrm{hf}}>\sim 33 \mathrm{~T}\right)$ and $\mathrm{Fe}(\mathrm{Co})$ oxides $(\delta=0.35$ $\left.\mathrm{mm} / \mathrm{s},\left\langle H_{\mathrm{hf}}\right\rangle \sim 35 \mathrm{~T}\right)$. Oxidized FeCoZr $-\mathrm{CaF}_{2}$ films with $x=74$ at.\% demonstrate a similar intensity ratio of spectral lines $(3: \sim 0.2: 1$, see Fig. 2a) as it was observed for non-oxidized ones. The spectra of films sintered at $P_{\mathrm{O}}=9.8 \mathrm{mPa}$ reveal a contribution from oxidized nanoparticles only.

Experimental dependencies of magnetoresistance $M R(H)$ $\left[=\left(R(H)-R_{0}\right) / R_{0}\right]$ for non-oxidized $(\mathrm{FeCoZr})_{\times}\left(\mathrm{CaF}_{2}\right)_{100-\mathrm{x}}$ films with lowest $x$ are presented in Fig. 3a. Negative MR observed for films with $x=24-33$ at.\% in the $T$ range $4-300 \mathrm{~K}$ evidences tunneling electrical conductivity. One should note a non-monotonous temperature dependency of $M R(H)$. In particular, for film with $x=24$ at.\% the maximal negative $M R$ effect was found at $T=150 \mathrm{~K}$ and further decrease of temperature resulted in a substantial decrease of magnitude of the $M R$ effect. The highest magnitude of the $M R$ value (about 2.7\%) was observed for $x=24$ at.\% film at $T=150 \mathrm{~K}$ and decreased rapidly with increasing alloy content $x$. Such temperature dependence of $M R$ with maximum within $T=150 \mathrm{~K}$ should be interpreted as the result of two competing processes - a decrease of thermal fluctuations effect that tends to enhance $M R$ at $T \geqslant 150 \mathrm{~K}$, on one hand, and vanishing of tunneling conductivity at $T<150 \mathrm{~K}$ because of lowering of electrons energy with decreasing $T$, on the other hand. A progressive decrease of $M R$ effect with $x$ up to zero value at $x=58$ at.\% (not shown), evidences the change of conductivity mechanism from tunneling to the metallic one due to percolation of metallic nano-

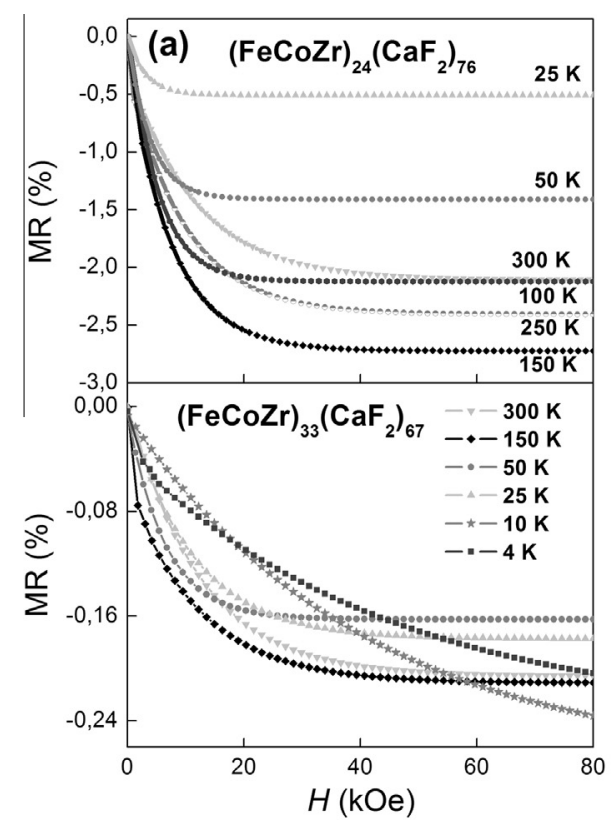

grains which is expected at high $x$ values. This conclusion is supported by the RT Mössbauer spectroscopy results which show SP-FM transition at threshold $x$ lower than 39 at.\% due to the formation of coupled or sufficiently large metallic $\alpha-\mathrm{FeCo}(\mathrm{Zr})$ nanoparticles.

Field dependencies of $M R$ for oxidized films (at $P_{\mathrm{O}}=4.3 \mathrm{mPa}$ ) are presented in Fig. 3b. It is seen that contrary to the case of films sintered in $\mathrm{Ar}$ atmosphere oxidized films demonstrate negative $M R$ in the broad $x$ range ( $x=37-63$ at.\%). This correlates with predominant formation of SP or weakly interacting nanoparticles at $x<74$ at.\% detected with Mössbauer spectroscopy. Simultaneously, it supported the assumption about the role of oxide shells in suppressing SP-FM transition and shifting corresponding threshold $x$ towards higher value in oxidized films.

Contrary to non-oxidized films (see Fig. 3a) $M R(H)$ curves for oxidized films (with comparable $x$ and size of nanoparticles are unsaturated up to $H=80 \mathrm{kOe}$ and demonstrate a monotonous increase of negative $M R$ effect with decreasing $T$ (see Fig. 3b). Moreover, oxidized films show higher $M R$ values for low $x$ (up to $7-8 \%$ at $T=10-25 \mathrm{~K}$ for samples with $x=37-49$ at.\%) as compared to non-oxidized ones. Basing on previous analysis of magnetometry and magnetoresistivity results for non-oxidized and oxidized FeCoZr- $\mathrm{Al}_{2} \mathrm{O}_{3}$ films [4], all the observed $M R(H)$ and $M R(T)$ dependencies in oxidized $\mathrm{FeCoZr}-\mathrm{CaF}_{2}$ films should be assigned to the formation of "metal core-oxide shell" structure of metallic nanoparticles due to their partial oxidation during synthesis in $\mathrm{Ar}+\mathrm{O}_{2}$ atmosphere. In particular, unsaturated $M R(H)$ curves at low $T$ are related to the disordered "frozen" spin states in oxide shells [3]. Oxide shells also contribute to the enhancement of $M R$ effect by stabilization of SP nanoparticles state and probably to a homogenization of their size distribution [6] as well as by possible "spinfiltering" process increasing polarization of tunneling electrons [7]. Unsaturated character and enhanced $M R$ at low temperatures should also be considered within the frame of high-order tunneling mechanism in the Coulomb blockage regime that was proposed for explanation of similar $M R$ peculiarities in Co-Al-O films [8].

Negative $M R$ effect is not detected in oxidized films sputtered at $P_{\mathrm{O}}=9.8 \mathrm{mPa}$ due to a full oxidation of metallic particles.

It is worth noting that partly oxidized $\mathrm{FeCoZr}-\mathrm{CaF}_{2}$ granular films demonstrate noticeably lower negative $M R$ effect at RT (up

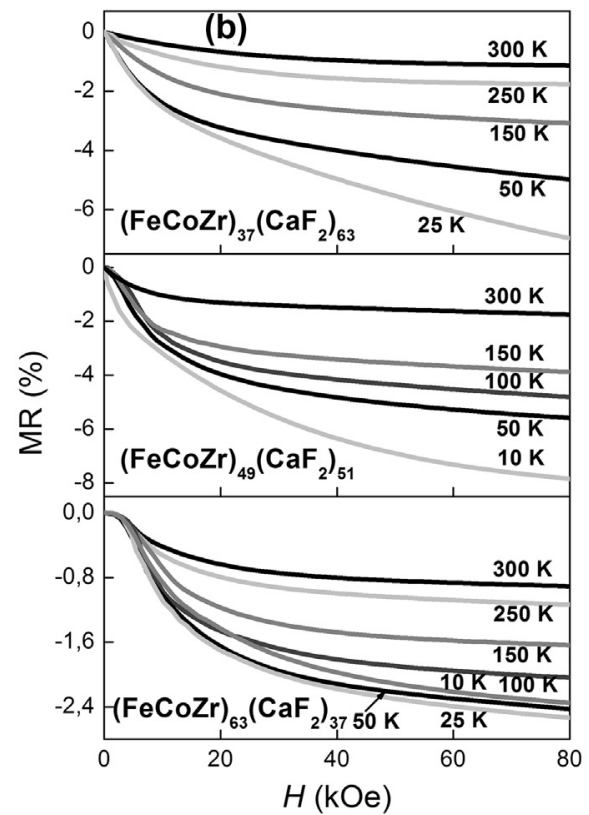

Fig. 3. Magnetoresistance $(\mathrm{MR})$ of selected $(\mathrm{FeCoZr})_{\mathrm{x}}\left(\mathrm{CaF}_{2}\right)_{100-\mathrm{x}}\left(24 \leqslant \mathrm{x} \leqslant 73\right.$ at.\%) granular films sintered in $\mathrm{Ar}(\mathrm{a})$ and $\mathrm{Ar}+\mathrm{O}_{2}$ at $P_{\mathrm{O}}=4.3 \mathrm{mPa}(\mathrm{b})$ atmospheres. 
to only $2 \%$ ) as compared with that is $\mathrm{FeCoZr}-\mathrm{Al}_{2} \mathrm{O}_{3}$ films (up to $6 \%$ [3]). Such a difference should be explained as a result of perpendicular shape magnetic anisotropy in $\mathrm{FeCoZr}-\mathrm{CaF}_{2}$ revealed by Mössbauer spectroscopy, in contrast to the case of $\mathrm{FeCoZr}-\mathrm{Al}_{2} \mathrm{O}_{3}$ films where magnetic moments of nanoparticles are oriented randomly [3]. Obviously, such a random orientation is more favorable for high $M R$ effect that depends mainly on the alignment of magnetic moments of nanoparticles due to the external magnetic field. In $\mathrm{FeCoZr}-\mathrm{CaF}_{2}$ films with magnetic anisotropy perpendicular to the film plane, application of perpendicular magnetic field will not influence the alignment of magnetic moments significantly, so that the MR effect will not be so high.

\section{Conclusions}

For the first time systematic study of granular films FeCoZr$\mathrm{CaF}_{2}$ films reveals strong relationship between atmosphere of deposition ( $\mathrm{Ar}$ or $\mathrm{Ar}+\mathrm{O}_{2}$ ), local Fe states, phase composition and magnetoresistance. In particular, granular $\mathrm{FeCoZr}-\mathrm{CaF}_{2}$ films sintered in $\mathrm{Ar}$ atmosphere contain $b c c \alpha$-Fe(Co) nanoparticles dispersed in crystalline $\mathrm{CaF}_{2}$ matrix. The threshold metal content for SP-FM transition at RT $x$ is below 39 at.\%. Negative MR effect of non-oxidized films decreases dramatically with increasing content $x$, that is attributed to a transition from tunneling conductivity in films with $x<58$ at.\% (maximal $M R$ effect of about $2.5 \%$ at $x=24$ at.\%) to a metallic conductivity at $x \geqslant 58$ at.\% (close to zero $M R$ effect) in strong correlation with films microstructure.

Contrary, synthesis of FeCoZr-CaF 2 granular films in $\mathrm{Ar}+\mathrm{O}_{2}$ atmosphere results in partial or full oxidation of nanoparticles, at $P_{\mathrm{O}}=4.3 \mathrm{mPa}$ and $9.8 \mathrm{mPa}$, respectively. Oxidized films sintered at $P_{\mathrm{O}}=4.3 \mathrm{mPa}$ contain $\alpha-\mathrm{FeCo}(\mathrm{Zr}), \mathrm{Fe}_{3} \mathrm{O}_{4}$ and/or $\alpha-\mathrm{Fe}_{2} \mathrm{O}_{3}$ phases and crystalline $\mathrm{CaF}_{2} \cdot{ }^{57} \mathrm{Fe}$ Mössbauer results for partly oxidized nanoparticles reveal the transition from SP and $\mathrm{Fe}^{3+}$ and $\mathrm{Fe}^{2+}$ oxides at lower $x$ (up to 36 at.\%) towards mixed magnetic state of SP and $\mathrm{FM}$ oxides and nonoxidized $\alpha-\mathrm{FeCo}(\mathrm{Zr})$ alloy at intermediate $\mathrm{x}=43$ at.\%. The threshold $x$ for SP-FM transition is shifted towards higher values (43 at.\%) as compared to non-oxidized films possibly due to formation of oxide shells on $\mathrm{FeCo}(\mathrm{Zr})$ metallic nanoparticles reducing their sizes and increasing their separation and, therefore, the magnetic coupling.

Such change of films microstructure due to the $\mathrm{Ar}+\mathrm{O}_{2}$ deposition atmosphere $\left(P_{\mathrm{O}}=4.3 \mathrm{mPa}\right)$ is also reflected in broadening of the films range, where tunneling $M R$ occurs ( $\mathrm{x}=37-63$ at.\%). In this case tunneling $M R$ in films with partly oxidized nanogranules is directly related to the formation of predominantly SP or weakly interacting nanoparticles in films where oxide shells suppressed SP-FM transition. Enhanced MR effect observed in these films is related to the stabilization of SP state, reduction of the nanoparticles size distribution as well as "spin-filtering" process that increase polarization of tunneling electrons due to the formation of "metal core - oxide shell" structure of nanoparticles.

Oxidized and non-oxidized $\mathrm{FeCoZr}-\mathrm{CaF}_{2}$ films with the highest $x=73-74$ at.\% exhibit perpendicular shape magnetic anisotropy originating from the formation of columnar agglomerations of nanoparticles. Such an anisotropy in oxidized $\mathrm{FeCoZr}-\mathrm{CaF}_{2}$ films $\left(P_{\mathrm{O}}=4.3 \mathrm{mPa}\right)$ with $(\mathrm{x} \sim 74$ at.\%) observed by Mössbauer spectroscopy is unfavorable for high MR effect.

In so doing, it is established and explained for the first time, that oxygen-containing atmosphere of deposition introducing "metal core - oxide shell" nanoparticles in granular films might be a powerful tool for tailoring and enhancement of magnetoresistance effect.

\section{Acknowledgement}

The financial support of Mianowski Fund (Warszawa) is gratefully acknowledged.

\section{References}

[1] F. Mazaleyrat, L.K. Varga, Journal of Magnetism and Magnetic Materials 215216 (2000) 253-259.

[2] B. Hackenbroich, H. Zare-Kolsaraki, H. Micklitz, Applied Physics Letters 81 (3) (2002) 514-516.

[3] J.A. Fedotova, J. Przewoznik, Cz. Kapusta, M. Milosavljevic, J.V. Kasiuk, J. Zukrowski, M. Sikora, A.A. Maximenko, D. Szepietowska, K.P. Homewood, Journal of Physics D: Applied Physics 44 (2011) 495001.

[4] F. Bodker, M.F. Hansen, Ch.B. Koch, K. Lefmann, S. Morup, Physical Review B 61 (10) (2000) 6826-6838.

[5] A.A. Timopheev, S.M. Ryabchenko, V.M. Kalita, A.F. Lozenko, P.A. Trotsenko, O.V. Stognei, A.V. Sitnikov, Physics of the Solid State 53 (3) (2011) 494-503.

[6] D.L. Peng, K. Sumiyama, T.J. Konno, T. Hihara, S. Yamamuro, Physical Review B 60 (4) (1999) 2093-2100.

[7] J.-H. Hsu, Ch.-R. Chang, Y.-H. Huang, IEEE Transactions on Magnetics 36 (5) (2000) 2815-2817.

[8] S. Mitani, S. Takahashi, K. Takanashi, K. Yakushiji, S. Maekawa, H. Fujimori, Physical Review Letters 81 (1998) 2799-2802. 